\title{
Neurosteroids and their neuroprotective actions
}

\author{
Kinga Borowicz-Reutt \\ Experimental Neuropathophysiology Unit, Department of Pathophysiology, Medical University Lublin, \\ Poland \\ Corresponding author: kingaborowicz@umlub.pl
}

\begin{abstract}
Background: From biochemical point of view neurosteroids are steroid hormone derivatives that devoid hormonal action but affect neuronal excitability through ionotropic receptors. Neurosteroids are further subdivided into natural (produced in the brain) and synthetic. Nevertheless, some authors subdivide also natural neurosteroids into hormonal and regular (non-hormonal) ones, for example two hormone metabolites (allopregnanolone and tetrahydrodeoxycorticosterone) that devoid of hormonal activity. Hormonal neurosteroids may present neuroprotective effects realized in both genomic and non-genomic mechanisms. In details, they involve regulation of the pro-and anti-apoptotic factors expression, intracellular signaling pathways, neurotransmission, oxidative, and inflammatory processes. Since regular neurosteroids show no affinity for steroid receptors, they may act only in a non-genomic mode. Conclusion: Many efforts have been done to show efficacy of neurosteroids in the treatment of the central and peripheral nervous system injury, ischemia, neurodegenerative diseases, or seizures. However, knowledge about neuroactive steroids remains incomplete and still requires confirmation in clinical conditions.
\end{abstract}

Keywords: Neurosteroids, Neurodegeneration, Neuroprotection

\section{INTRODUCTION}

Despite intensive research, there is still a lack of medications with proved neuroprotective action in clinical conditions. Due to their specific mechanisms of action, neurosteroids may be considered as substances with possible neuroprotective effects. According to the broadest definition, neurosteroids cover both steroids (synthesized in vivo in neurons and glial cells) and their metabolites acting within the brain (Compagnone \& Mellon, 2000). Hormones bind to membrane and nuclear receptors (Plassart-Schiess \& Baulieu, 2001; Singh, 2006). In contrast, regular neurosteroids act only on membrane ionotropic receptors as their positive or negative modulators: gamma-amino butyric acid $\mathrm{A}\left(\mathrm{GABA}_{\mathrm{A}}\right)$ receptor, $\mathrm{N}$ methyl-D-aspartate (NMDA) receptor, $\alpha$-amino-3-hydroxy-5-methylisoxazole propionate (AMPA) receptor, sigma 1, nicotinic, muscarinic, kainic, serotonergic receptors (Borowicz, et al, 2000). The present review summarizes the action of pregnenolone (PREG), pregnenolone sulphate (PREGS), progesterone (PROG), allopregnanolone (ALLO), dehydrepiandrosterone (DHEA) and its sulphate (DHEAS), deoxycorticosterone (DOC), and tetrahydrodeoxycorticosterone (THDOC). Among them PREG is a hormone precursor, PROG, DOC, and DHEA represent natural hormones, while ALLO (a PROG metabolite) and THDOC (a DOC derivative) belong to neurosteroids with no hormonal action. Synthetic neurosteroids have better bioavaiability, longer half-time, and may be administered orally, in contrast to natural steroids (Borowicz, et al, 2000; Wojtal, et al, 2006).

Neuroprotection means protection against neuronal injury or degeneration, which may result from acute disorders, such as stroke or nervous system injury, or chronic neurodegenerative processes (e.g., in the course of Alzheimer's, Parkinson's, and Huntington's disease). The ideal neuroprotectant should prevent the development of a disease, but this aim is at present impossible to achieve. However, it is equally important to limit neuronal dysfunction after the CNS injury and maintain possibly undisturbed neural function and cellular integrity.

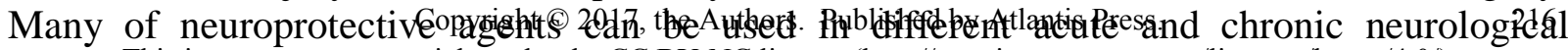


disorders, because most of the underlying mechanisms of neurodegeneration (in both acute and chronic disorders) seems to be quite similar.

Until recently two basic mechanisms of cell death were known: the programmed cell death (apoptosis) and unregulated process of necrosis. Necrosis and apoptosis differ with numerous morphological and biochemical features. In necrosis, extreme physiological conditions (e.g., hypoxia) lead to damage to the plasma membrane and finally cell lysis. Apoptosis (programmed cell death), regulated by caspase cascade, is characterized by cytoplasmic and nuclear vacuolization, as well as cell shrinking (Sperandio, et al, 2010; Yakovlev \& Faden, 2004). However, increasing evidence indicates that necrotic cell death can also be a regulated process. The term necroptosis was introduced to describe this alternative form of cell death - the programmed necrosis (Vandenabeele, et al, 2010). Necroptosis is defined as a programmed but caspase-independent cell death that morphologically resembles necrosis (Degterev, et al, 2005). This process, in fact intermediate between necrosis and apoptosis, accompanies often hypoxia, reperfusion, and excitotoxicity. Further research on neuronal death mechanisms may help to develop an effective neuroprotective strategy and improve the patient quality of life (Charalampopoulos, et al, 2008).

\section{PREGNENOLONE}

Pregnenolone, a neurosteroid precursor, exhibited neuroprotective effects against glutamate- and amyloid $\beta$ protein-induced neurotoxicity in clonal mouse hippocampal cells (Gursoy, Cardounel, \& Kalimi, 2001). It also stabilized microtubules (Hsu, et al, 2006), activated neurite outgrowth in nerve growth factor-pretreated clonal rat pheochromocytoma cell line (Fontaine-Lenoir, et al, 2006) and improved myelination (Koenig, et al, 1995). Moreover, PREG diminished the number of apoptotic cells in primary neuronal cortical cultures ( $\mathrm{Li}$, et al, 2009) and exerted neuroprotective effects against kainate-induced cell death in the rat hippocampus. Interestingly, mechanism of this action may be mediated by estradiol, the main product of aromatase action on PREG. Fadrozole, an aromatase inhibitor, prevented the neuroprotective effects of both PREG and estradiol (Veiga, et al, 2003).

In patients with Alzheimer's disease, PREG concentrations were reduced in the striatum and cerebellum. Furthermore, higher levels of PREG were correlated with lower content of cortical $\beta$-amyloid (Weill-Engerer, et al, 2003).

\section{PROGESTERONE AND DERIVATIVES}

Progesterone is produced primarily in females (in ovaries, corpus luteum and placenta), while in males in testes and adrenal glands. However, this gestagen may be also synthesized de novo within the brain in both neurons and glial cells (Corpéchot, et al, 1983).The hormone and its derivatives are positive modulators of $\mathrm{GABA}_{\mathrm{A}}$ receptors (Borowicz, et al, 2000). It seems that action of this hormone is not mediated by steroid receptor since it occurs quickly (within minutes) and is not blocked by the respective receptor antagonist - RU486.

Roof et al. (1997) reported also antioxidant action of PROG. Identification of neuroprotective properties of this steroid began with the observation of a better recovery (decreased edema and cognitive impairment) of female pseudopregnant rats after the traumatic brain injury (Roof et al. (1997). However, the positive effect of PROG could be achieved when the steroid is administered within $24 \mathrm{~h}$ after injury - the sooner onset means the better outcome (Stein, 2008). Furthermore, Shear et al. (2002) reported that 3- and 5-days treatment with PROG after TBI resulted in a significant reduction of injury-induced necrosis, diminished cell loss, and facilitated behavioral recovery of animals.

Advantageous properties of PROG were also observed in models of the spinal cord and peripheral nerve injury. The hormone administered for 3 days following the spinal cord injury improved myelination, increased the level of brain derived neurotrophic factor (DeNicola, et al, 2012) whereas 5-day administration diminished the size of necrosis, prevented secondary 
neuronal loss, and increased axonal regeneration (Thomas, et al, 1999). In addition, this steroid acts as a promyelinating factor by stimulating synthesis of myelin proteins and proliferation/differentiation of oligodendrocyte progenitors (Gonzales, et al, 2015). In rat peripheral nerves PROG increased glial cell growth and differentiation, induced synthesis of myelin-specific proteins in oligodendrocytes, and induced the formation of new myelin sheaths by Schwann cells (Baulieu, \& Schumacher, 2000). Progesterone administration following the cortical contusion injury protected against secondary neuronal loss and facilitated cognitive recovery in rats (Roof, et al, 1994). Post-injury administration of PROG in rats with the brain global ischemia resulted in a significant reduction of cortical shrinkage, hippocampal cell loss and ventricular dilatation compared with control animals (Naylor, et al, 2004). In permanent middle cerebral artery occlusion model in rats, this steroid diminished cortical and optionally subcortical infarct volumes (Alkayed, et al, 2000). Recently, Cai et al. (2008) found that acute neuroprotective effects of PROG in ischemic brain injury may depend on its antagonistic action toward the $\sigma 1$ receptor and subsequent inhibition of the NMDA-induced Ca influx. Finally, PROG was investigated in the ProTECT clinical study. It was observed that patients with acute TBI, treated with PROG, had a lower mortality rate than control individuals (Wright, et al, 2015). Similarly, lower mortality and better functional outcomes were found in the PROG group of patients by Xiao et al. (2008) and Stein and Wright (2010).

Neuroprotective effects of PROG were also shown in animal models of spinal cord degeneration. Wobbler mice receiving the hormon presented less pronounced neuropathology and apoptosis (Gonzales, et al, 2002). PROG attenuated also motoneuron degeneration and boosted myelination in Schwann cells and oligodendrocytes in the CNS (Gonzales, et al, 2002). Neuroprotective properties of PROG and ALLO were shown by Leonelli et al. (2007) in streptozotocin-induced diabetic neuropathy model in rats. Chronic (1 month lasting) treatment with these neurosteroids preserved the nerve conduction velocity, thermal threshold, intraepidermal nerve fiber density, $\left.\mathrm{Na}^{+}\right) \mathrm{K}\left({ }^{+}\right)$-ATPase activity, and levels of myelin proteins (Leonelli, et al, 2007).

Neuroprotective action of PROG seem to be partially due to reduction of cerebral edema that may be achieved via different mechanisms. Other possible actions of PROG include: down-regulation of the inflammatory cascade by decelerating cytokine (IL-1;IL- 6; $\mathrm{TNF} \alpha$ )-induced reactions, slowing the immune cell activation, and migration (Grossman, et al, 2004). This neurosteroid limits cellular necrosis and apoptosis by: 1. Lowering the concentration of nuclear factor $\kappa \beta$ (Pettus et al, 2005). 2. Reducing excitotoxicity by inhibition of glutamate receptors, 3 . boosting the effects of $\mathrm{GABA}_{\mathrm{A}}$, 4. depression of spontaneous firing of neurons, a causative factor of posttraumatic seizures (Stein, 2008), 5. stimulation of Schwann's cells to produce myelin, and reducing glial scarring in the CNS (Koenig, et al, 2009), 6. Decreasing injury-induced lipid peroxidation and oxidative stress via inhibition of TNF- $\alpha$ production or up-regulation of antioxidant enzymes (Roof, et al 1997; Stein, 2008; Stein \& Wright, 2010). It is aso worth mentioning that PROG increased expression of the antiapoptotic genes (Bcl-2, Bcl-x) and decreased expression of pro-apoptotic (bax and bad) genes (Yao, et al, 2005).

PROG derivative (ALLO), administered in rats after TBI, decreased apoptosis and improved behavioral outcome of animals similarly to the maternal drug (Djebaili et al, 2005). ALLO and PROG protected the rat brain from post-injury edema and decreased production of pro-inflammatory cytokines (IL-1,TNF- $\alpha$ ). In patients with Alzheimer's disease, the level of ALLO in the temporal cortex was significantly lower than in controls, in contrast to PREG and DHEA which concentrations were increased (Naylor, et al, 2008). Furthermore, ALLO enhanced myelination and reduced inflammatory processes in the animal model of NiemannPick type C disease (Melon, et al, 2008). Callier et al. (2001) revealed that PROG protected dopaminergic neurons against MPTP-induced degeneration in rats (the animal model of Parkinson's disease). Moreover, in MPTP-treated mice, PROG did not reverse the protective 
effect of estrogens on dopamine neurons. In patients with Parkinson's disease, lower concentrations of PROG and ALLO than in controls were found in the cerebrospinal fluid (Luchetti, et al, 2011). Similarly, diminished ALLO concentration and reduced activity of enzymes synthesizing the neurosteroid were found in patients with multiple sclerosis (Luchetti, et al, 2011). Moreover, ALLO diminished NMDA-induced toxicity, decreased expression of pro-apoptotic genes and enhanced expression of $\mathrm{GABA}_{\mathrm{A}}$ receptor subunits, so their neuroprotective action seems to be mediated by enhanced GABA-ergic neurotransmission (Xilouri \& Papazafiri, 2006).

ALLO appears to play a significant role in the pathogenesis of Alzheimer's disease. Reduced levels of this steroid were found in the patient plasma and prefrontal cortex (Luchetti, et al, 2011). In the mouse model of Alzheimer's disease PROG treatment improved cognitive functions, but on the other hand, antagonized beneficial effects of estrogens in reducing $\beta$ amyloid deposits. It is possible that the sequential therapy with estrogen and PROG may bring better results than the treatment with only one hormone (Pike, et al 2009).

At present, more than 180 articles showed protective activity of PROG in both experimental animals and humans. Moreover, two independent phase II clinical trials revealed that PROG significantly improved survival and functional outcomes in patients after stroke. Nevertheless, in some experimental studies PROG was not effective or even worsen the prognosis of animals after TBI or ischemic injury (Stein, 2008). However, the probable reason of PROG treatment failure may be advanced age of used animals.

PROG and ALLO exhibited also anticonvulsive properties, for instance in kainicinduced seizures and amygdala-kindled rats (Holmes \& Weber, 1984). Growing evidence suggests that anticonvulsive and neuroprotective properties of PROG are mediated by its metabolites 5 $\alpha$-DHP and ALLO, positive modulators of GABAA receptors (Stevens \& Harden, 2011).

\section{DEHYDROEPIANDROSTERONE AND DEHYDROEPIANDROSTERONE SULFATE ESTER}

Dehydroepiandrosterone (DHEA) and its sulfate ester (DHEAS) were reported to act as neuroprotective and anti-excitatory factors. Protective properties of DHEA may be related to inhibition of the NMDA-induced nitric oxide (NO) production or modulation of the calcium/NO signaling pathway. The action of this hormone can be also mediated by sigma receptors. Additionally, DHEAS was shown to attenuate the destructive action of glutamate and NMDA on cerebellar granule cells in rats. Protective effects of both DHEA and DHEAS can be realized through preventing the mitochondria against intracellular $\mathrm{Ca}^{2+}$ overload (Mao \& Barger, 1998). Time- and dose-dependent neuroprotective action of DHEA was documented in the in vivo model of global cerebral ischemia in rats. Administration of DHEA during 3-48 $\mathrm{h}$ after ischemia reduced neuronal death in the hippocampal CA1 region and ameliorated ischemia-induced deficits in spatial learning. Whereas, the treatment of DHEA $1 \mathrm{~h}$ before or after ischemia may intensify the ischemia-induced neuronal damage and learning failure. This study may suggest that DHEA, dependently on time of treatment, exhibits a dual action - it may be either neurotoxic or neuroprotective (Roof, et al, 1997). DHEAS may protect neurons against ischemia by activation of sigma-1 receptor (Cheng et al, 2008). DHEAS has been also investigated in the reversible spinal cord ischemia model. The neurosteroid exhibited a preventive effect when it was administered $5 \mathrm{~min}$, but not $30 \mathrm{~min}$ after ischemia. The beneficial effect of DHEA was reversed by bicuculline, the $\mathrm{GABA}_{\mathrm{A}}$ antagonist, which indicates GABAergic mechanism of the neurosteroid action (Lapchak, et al, 2000). Aforementioned results show that DHEA and DHEAS may provide neuroprotection against ischemia. However, it should be remembered that DHEA administered during ischemia maybe also neurotoxic.

According Kimonides et al. (1998), DHEA showed a dose-dependent neuroprotective 
effect against glutamate excitotoxicity mediated by NMDA receptors (in vivo and in vitro) or evoked by AMPA/KA receptor agonists (in vitro). Decreased levels of DHEA in aging people may increase vulnerability of the brain to such a damage. Age-related declines of neurosteroids have been postulated to play a role in the pathogenesis of neurodegenerative diseases (Naylor, et al 2008).

Some results suggest that DHEAS may be a negative modulator of $\mathrm{GABA}_{\mathrm{A}}$ receptors. On the other hand, this neurosteroid exhibits anticonvulsive action against NMDA- and ironinduced seizures (Mishra, Singh \& Sharma, 2010). Further, DHEA was reported to reduce the extent of denervation atrophy. The neurosteroid accelerated also axonal regeneration (Ayhan, et al 2003) and increased the number of myelinated fibers and fiber diameters after sciatic nerve transection in rats (Gudemez, et al 2002).

According to Frye and Reed (1998), a $3 \alpha$-Diol metabolite of another androgen (testosterone) exhibited anticonvulsive effect against seizures induced in rats by kainate or perforant pathway stimulation. Moreover, the neurosteroid reduced hippocampal cell death and improved animal performance in the Morris water maze. Interestingly, this action was inhibited by $\mathrm{GABA}_{\mathrm{A}}$ receptor blockade, therefore it is not clear whether the action of $3 \alpha$-Diol is due to enhanced GABA-ergic neurotransmission or to increased estrogen concentration.

\section{DEOXYCORTICOSTERONE AND ALLOTETRAHYDRODEOXYCORTICOSTERONE}

Although there is no literature data on neuroprotective properties of deoxycorticosterone (DOC) and its derivative allotetrahydrodeoxycorticosterone (THDOC), the two neurosteroids exhibited some anticonvulsive effects. THDOC protected against convulsions induced by various $\mathrm{GABA}_{\mathrm{A}}$ receptor antagonists, like picrotoxin, pentylenetetrazole, or bicuculline, and the glutamate receptor agonists, such as kainic acid or NMDA. In human studies, decreased serum level of THDOC was found in women with catamenial epilepsy, which may indicate a role of this neurosteroid in the pathophysiology of perimenstrual seizures. The antiseizure effect of THDOC seems to depend on positive allosteric modulation of $\mathrm{GABA}_{\mathrm{A}}$ receptor (Rogawski \& Reddy, 2004).

\section{SYNTHETIC NEUROSTEROIDS}

The main disadvantage of natural neurosteroids is their short biological half-life. Therefore some modified derivatives were synthesized in order to inhibit their metabolism. Neurosteroid analogs offered mainly a broad spectrum of anticonvulsive activity in different experimental seizure models. Therefore, they are mostly considered as a novel class of antiepileptic medications. The leading example is ganaxolone, a representative of III generation antiepileptic drugs.

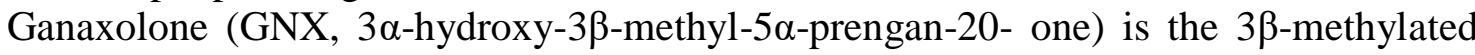
analog of ALLO. As the parent compound, GNX is a positive allosteric modulator of GABA $A$ receptors and increases chloride inward current within the $\mathrm{GABA}_{\mathrm{A}}$-benzodiazepine receptor complex (Nohria \& Giller, 2007). The neurosteroid exhibited effectiveness in a variety of animal models of epilepsy, including convulsions induced by pentylenetetrazole, bicuculline, fluorothyl, cocaine, aminophylline, as well as in pentylenetetrazole kindling, amygdala kindling, and $6 \mathrm{~Hz}$ electrical stimulation (Gasior et al, 2000; Kaminski, et al, 2004; Rogawski $\&$ Reddy, 2004). On the other hand, this ALLO analog proved to be ineffective against NMDA- and strychnine-induced seizures in mice (Gasior, et al, 1997). The neurosteroid may be very valuable in the treatment of temporal lobe epilepsy. However, most data suggests that GNX might provide a specific treatment for catamenial epilepsy in humans. In clinical studies, GNX was shown to be well tolerated in adults and children. In early phase II studies, GNX was 
found to be effective in adult patients with partial-onset seizures and in epileptic children with infantile spasms. Currently, further investigations are conducted in infants with newly diagnosed infantile spasms, women with catamenial epilepsy, and adults with refractory partial-onset seizures.

It was recently reported that the pretreatment with a new synthesized analog of ALLO, 3a-hydroxy-21,22-oxido-21-homo-5a-pregnan-20-on (HOHP), suppressed generalized tonicclonic seizures in pentylenetetrazol-induced seizures in mice, and efficacy of this analog resembled that of GNX (Mareš,, Kubova, \& Kasal ., 2010).

Two synthetic neurosteroids, minaxolone $(2 \beta, 3 \alpha, 5 \alpha, 11 \alpha)$-11-(dimethylamino)-2-

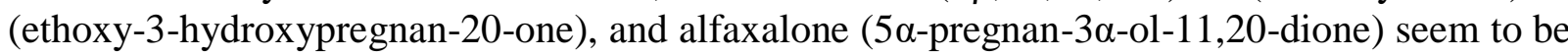
effective positive allosteric modulators of the $\alpha 1$ glycine receptor (Maksay \& Biro,2002). Both analogs proved efficacy against pentylenetetrazole- and bicuculline-induced convulsions in animals. Alphaxalone showed, moreover, a moderate anticonvulsive activity in amygdalakindled rats and maximal electroshock in mice (Rogawski \& Reddy, 2004).

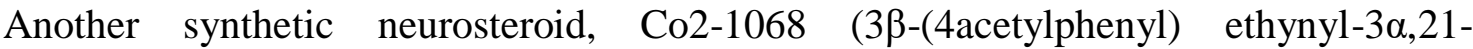
dihydroxy-5 $\beta$-20-one-21-hemisuccinate) was reported to be effective against pentylenetetrazole-, NMDA-, and cocaine-induced seizures in mice (Gasior, et al, 1997).

So far, only fluasterone (DHEF), a novel DHEA analog, was considered as a candidate for a drug used in the treatment of TBI in humans. This steroid was reported to improve functional recovery in the rat TBI model. Possible DHEF mechanisms of action are still unclear. According to Malik et al. (2003), this neurosteroid exhibited anti-inflammatory action, markedly inhibiting synthesis of prostaglandin (PGE2) and interleukin-1ßa-induced cyclooxygenase-2 (COX2) in cultures of rat mesangial, but not cortical or hippocampal cells (Malik, et al 2003).

\section{CONCLUSION}

Neurosteroids may exhibit neuroprotective effects. These natural and synthetic substances attenuate excitotoxicity, brain edema, inflammatory processes, oxidative stress, and neural degeneration. Additionally, neurosteroids accelerate and improve regeneration and myelination. Promising results of preclinical studies indicate possible profits of neurosteroid treatment in the treatment of different diseases, especially the brain and spinal cord injury, stroke, Parkinson's and Alzheimer's diseases, or epilepsy. Unfortunately, therapeutic application of natural neurosteroids was significantly limited by its rapid biotransformation. Only synthetic analogs, particularly ganaxolone or $3 \alpha$-ol-5 $\beta$-pregnan-20-one, can be considered as potential anticonvulsive drugs. In fact, ganaxolone has been already classified to antiepileptic drugs of III generation. This gives a real hope that neurosteroids can be also used as effective neuroprotective drugs.

\section{REFERENCES}

Alkayed, N.J., Murphy, S.J., Traystman, R. J., Hurn, P.D. and Miller,V.M., (2000). Neuroprotective effects of female gonadal steroids in reproductively senescent female rats. Stroke 31:161-168.

Arvin, B., Neville, L.F., Barone, F.C. and Feuerstein, G.Z., (1996). The role of inflammation and cytokines in brain injury. Neurosci. Biobehav. Rev. 20:445-452.

Ayhan, S., Markal, N., Siemionow, K., Araneo, B. and Siemionow, M., (2003). Effect of subepineurial dehydroepiandrosterone treatment on healing of transected nerves repaired with the epineurial sleeve technique. Microsurgery 23:49-53.

Baulieu, E.E. and Schumacher, M., (2000). Progesterone as a neuroactive neurosteroid, with 
special reference to the effect of progesteroneon myelination. Steroids 65:605-612.

Borowicz, K.K., Golyska, D., Morawska, M. and Furmanek-Karwowska, K.,(2008). Neuroprotective properties of neurosteroids. Epileptologia 16:59-68.

Cai, W., Zhu,Y., Furuya, K., Li, Z., Sokabe, M. and Chen, L., (2008). Two different molecular mechanisms underlying progesterone neuroprotection against ischemic brain damage. Neuropharmacology 55:127-138.

Callier, S., Morissette, M., Grandbois, M., Pelaprat, D. and DiPaolo, T., (2001). Neuroprotective properties of 17beta-estradiol, progesterone, and raloxifene in MPTPC57B1/6 mice. Synapse 41:131-138.

Charalampopoulos, I., Remboutsika, E., Margioris, A.N. and Gravanis, A., (2008). Neurosteroids as modulators of neurogenesis and neuronal survival. Trends Endocrinol. Metab. 19:300-307.

Cheng, Z.X., Lan, D.M.,Wu, P.Y., Zhu, Y.H., Dong, Y., Ma, L. and Zheng, P, (2008). Neurosteroid dehydroepiandrosterone sulphate inhibits persistent sodium currents in rat medial prefrontal cortex via activation of sigma-1 receptors. Exp. Neurol. 210:128-136.

Compagnone, N.A. and Mellon, S.H., (2000). Neurosteroids: biosynthesis and function of these novel neuromodulators. Front. Neuroendocrinol. 21:1-56.

Corpéchot, C., Synguelakis, M., Talha, S., Axelson, M., Sjövall, J., Vihko, R., Baulieu, E.E. and Robe 1,P., (1983). Pregnenolone and its sulfate ester in the rat brain. Brain Res. 270:119-125.

Czlonkowska, A.I., Krzascik, P., Sienkiewicz-Jarosz, H., Siemiatkowski, M., Szyndler, J., Bidzinski, A., and Plaznik, A., (2000). The effects of neurosteroids on picrotoxin-, bicuculline- and NMDA-induced seizures, and a hypnotic effect of ethanol. Pharmacol. Biochem. Behav. 67:345-353.

Degterev, A., Huang, Z., Boyce, M., Li, Y., Jagtap, P., Mizushima, N., Cuny, G.D., Mitchison, T.J., Moskowitz, M.A. and Yuan, J., (2005). Chemical inhibitor of nonapoptotic cell death with therapeutic potential or ischemic brain injury. Nat. Chem. Biol. 1:112-119.

DeNicola, A.F., Gonzalez, S.L., Labombarda, F., Gonzalez Deniselle, M.C., Garay, L., Guennoun, R. and Schumacher, M., (2006). Progesterone treatment of spinal cord injury: effects on receptors, neurotrophins, and myelination. J. Mol. Neurosci. 28:3-15.

Djebaili, M., Guo, Q., Pettus, E.H., Hoffman, S.W. and Stein, D.G., (2005). The neurosteroids progesterone and allopregnanolone reduce cell death, gliosis, and functional deficits after traumatic brain injury in rats. J. Neurotrauma 22:106-118.

Fontaine-Lenoir,V., Chambraud, B., Fellous, A., David, S., Duchossoy, Y., Baulieu, E.E. and Robel, P., (2006). Microtubule-associated protein 2 (MAP2) isaneurosteroid receptor. Proc. Natl. Acad. Sci. U.S.A. 103:4711-4716.

Frye, C.A. and Reed, T.A., (1998). Androgenic neurosteroids: anti-seizure effects in an animal model of epilepsy. Psychoneuroendocrinology 23:385-399.

Gasior, M., Carter, R.B., Goldberger, S.R. and Witkin, J.M., (1997). Anti- convulsant and behavioral effects of neuroactive steroids alone and in conjunction with diazepam. J. Pharmacol. Exp. Ther. 282:543-552.

Gasior, M., Ungard, J.T., Beekman, M., Carter, R.B. and Witkin, J.M., (2000).Acute and chronic effects of the synthetic neuroactive steroid, ganaxolone, against the convulsive and lethal effects of pentylenetrazol in seizure-kindled mice: comparison with diazepam and valproate. Neuropharmacology 39:1184-1196.

Gonzalez, S.L., Labombarda, F., Gonzalez Deniselle, M.C., Mougel, A., Guennoun, R., Schumacher, M. and De Nicola, A.F., (2005). Progesterone neuroprotection in spinal cord trauma involves up-regulation of brain-derived neurotrophic factor in motoneurons. J. Steroid Biochem. Mol. Biol. 94:143-149.

Gonzalez Deniselle, M.C., Lopez Costa, J.J., Gonzalez, S.L., Labombarda, F., Garay, L., 
Guennoun, R., Schumacher, M. and De Nicola, A.F., (2002). Basis of progesterone protection in spinal cord neurodegeneration. J. Steroid Biochem. Mol. Biol. 83:199209.

Grossman, K.J., Goss, C.W. and Stein, D.G., (2004). Effects of progesterone on the inflammatory response to brain injury in the rat. Brain Res. 1008:29-39.

Gudemez, E., Ozer, K., Cunningham, B., Siemionow, K., Browne, E. and Siemionow, M., (2002). Dehydroepiandrosterone as an enhancer of functional recovery following crush injury to rat sciatic nerve. Microsurgery 22:234-241.

Gursoy, E., Cardounel, A. and Kalimi, M., (2001). Pregnenolone protects mouse hippocampal (HT- 22) cells against glutamate and amyloid beta protein toxicity. Neurochem. Res. 26:15-21.

Holmes, G. L. and Weber, D. A., (1984). The effect of progesterone on kindling: a developmental study. Brain Res. 318:45-53.

Hsu, H.J., Liang, M.R., Chen, C.T. and Chung, B.C., (2006). Pregnenolone stabilizes microtubules and promotes zebrafish embryonic cell movement. Nature 439:480-483.

Jung-Testas, I., Hu, Z.Y., Baulieu, E.E. and Robel, P., (1989). Neurosteroids: biosynthesis of pregnenolone and progesterone in primary cultures of rat glial cells. Endocrinology 125:2083-2091.

Kaminski, R.M., Livingood, M.R. and Rogawski, M.A., 2004. Allopregnanolone analogs that positively modulate GABA receptors protect against partial seizures induced by $6 \mathrm{~Hz}$ electrical stimulation in mice. Epilepsia 45:864-867.

Kimonides,V.G., Khatibi, N.H, Svendsen, C.N., Sofroniew, M.V. and Herbert, J., (1998). Dehydroepiandrosterone (DHEA) and DHEA-sulfate (DHEAS) protect hippocampal neurons against excitatory amino acid-induced neurotoxicity. Proc. Natl. Acad. Sci. U.S.A. 1795:1852-1857.

Koenig, H.L., Schumacher, M., Ferzaz, B., Thi, A.N., Ressouches, A., Guennoun, R., JungTestas, I., Robel, P., Akwa, Y. and Baulieu, E.E., (1995). Progesterone synthesis and myelin formation by Schwann cells. Science 268: 1500-1503.

Kroemer, G., Galluzzi, L.,Vandenabeele, P., Abrams, J., Alnemri, E.S., Baehrecke, E.H., Blagosklonny, M.V., El-Deiry,W.S., Golstein, P., Green, D.R., Hengartner, M., Knight, R.A., Kumar, S., Lipton, S.A., Malorni, W., Nuñez, G., Peter, M.E., Tschopp, J.,Yuan, J., Piacentini, M., Zhivotovsky, B. and Melino, G., (2009). Classification of cel death: recommendations of the Nomenclature Committee on Cell Death 2009. Cell Death Differ. 16:3-11.

Labombarda, F., González Deniselle, M.C., DeNicola, A.F. and González, S.L., (2010). Progesterone and the spinal cord: good friends in bad times. Neuroimmunomodulation 17:146-149.

Lapchak, P.A., Chapman, D.F., Nunez, S.Y. and Zivin, J.A., (2000). Dehydroepiandrosterone sulfate is neuroprotective in a reversible spinal cord ischemia model: possible involvement of GABA(A) receptors. Stroke 31:1953-1956.

Leonelli, E., Bianchi, R., Cavaletti, G., Caruso, D., Crippa, D., Garcia-Segura, L.M., Lauria,G., Magnaghi, V., Roglio, I. and Melcangi, R.C., (2007). Progesterone and its derivatives are neuroprotective agents in experimental diabetic neuropathy: a multimodal analysis. Neuroscience 144:1293-1304.

Leskiewicz, M., Budziszewska, B., Jaworska-Feil, L. and Lason, W., (1997). Effects of neurosteroids on kainate-induced seizures, neurotoxicity and lethality in mice. Pol. $J$. Pharmacol. 49:411-417.

Leskiewicz, M., Jantas, D., Budziszewska, B. and Lason, W., (2008). Excitatory neurosteroids attenuate apoptotic and excitotoxic cell death in primary cortical neurons. J. Physiol. Pharmacol. 59:457-475.

Li, Z., Cui, S., Zhang, Z., Zhou, R., Ge, Y., Sokabe, M. and Chen, L., (2009). DHEA- 
neuroprotection and neurotoxicity after transient cerebral ischemia in rats. J. Cereb. Blood Flow Metab. 29:287-296.

Liao, G., Cheung, S., Galeano, J., Ji, A.X., Qin, Q. and Bi, X., (2009). Allopregnanolone treatment delays cholesterol accumulation and reduces autophagic/lysosomal dysfunction and inflammation in Npc1- /- mousebrain. Brain Res. 1270:140-151.

Luchetti, S., Huitinga, I. and Swaab, D.F., (2011). Neurosteroid and GABA-A receptor alterations in Alzheimer's disease, Parkinson's disease and multiple sclerosis. Neuroscience 191:6-21.

Maksay, G. and Biro, T., (2002). Dual cooperative allosteric modulation of vinding to ionotropic glycine receptors. Neuropharmacology 43:597-602.

Mao, X. and Barger, S.W., (1998). Neuroprotection by dehydroepiandrosterone-sulfate: role of an NF kappa B-like factor. Neuroreport 9:759-763.

Malik, A.S., Narayan, R.K., Wendling, W.W., Cole, R.W., Pashko, L.L., Schwartz, A.G. and Strauss, K.I., (2003). A novel dehydroepiandrosterone analog improves functional recovery in a rat traumatic brain injury model. J. Neurotrauma 20:463-476.

Mareš, P., Kubova, H. and Kasal A., (2010). Anticonvulsant action of a new analogue of allopregnanolone in immature rats. Physiol. Res. 59:305-308,

Mellon, S.H., Gong,W. and Schonemann, M.D., (2008). Endogenous and synthetic neurosteroids in treatment of Niemann-Pick Type C disease. Brain Res. Rev. 57:410 420.

Mishra, M., Singh, R. and Sharma, D., (2010). Antiepileptic action of exogenous dehydroepiandrosterone in iron-induced epilepsy in rat brain. Epilepsy Behav. 19:264271.

Moralí, G., Letechipía-Vallejo, G., López-Loeza, E., Montes, P., Hernández-Morales, L. and Cervantes, M., (2005). Post-ischemic administration of progesterone in rats exerts neuroprotective effects on the hippocampus. Neurosci. Lett. 382:286-290.

Naylor, J.C., Hulette, C.M., Steffens, D.C., Shampine, L.J., Ervin, J. F., Payne,V.M., Massing, M.W., Kilts, J.D., Strauss, J.L., Calhoun, P.S.,Calnaido, R.P.,Blazer, D.G., Lieberman, J.A., Madison, R.D. and Marx, C.E., (2008). Cerebrospinal fluid dehydroepiandrosterone levels are correlated with brain dehydroepiandrosterone levels, elevated in Alzheimer's disease, and related to neuropathological disease stage. J. Clin. Endocrinol. Metab. 93:3173-3178.

Nohria,V. and Giller, E., (2007). Ganaxolone. Neurotherapeutics 4:102-105.

Pettus, E.H.,Wright, D.W., Stein, D.G. and Hoffman, S.W., (2005). Progesterone treatment inhibits the inflammatory agents that accompany traumatic brain injury. Brain Res. 1049:112-119.

Pike, C.J., Carroll, J.C., Rosario, E. R. and Barron, A.M., (2009). Protective actions of sex steroid hormones in Alzheimer's disease. Front. Neuroendocrinol. 30:239-258.

Plassart-Schiess, E. and Baulieu, E.E., (2001). Neurosteroids: recent findings. Brain Res. Rev. 37:133-140.

Reddy, D.S. and Rogawski, M.A., (2000a). Chronic treatment with the neuroactive steroid ganaxolone in the rat induces anticonvulsant tolerance to diazepam but not to itself. J. Pharmacol. Exp. Ther. 295:1241-1248.

Reddy, D.S. and Rogawski, M.A., (2000b). Enhanced anticonvulsant activity of ganaxolone after neurosteroid withdrawal in a rat model of catamenial epilepsy. J. Pharmacol. Exp. Ther. 294:909- 915.

Reddy, D.S. and Rogawski M.A., (2009). Neurosteroid replacement therapy for catamenial epilepsy. Neurotherapeutics 6:392-401.

Rogawski, M.A. and Reddy, D.S., (2004). "Neurosteroids: endogenous modulators of seizures susceptibility, ” in Epilepsy: Scientific Foundations of Clinical Practive, eds J.M. Rho, R. Sankar and J.Cavazos (New York: Marcel Dekker),319-355. 
Roof, R.L., Duvdevani, R., Braswell, L. and Stein, D.G., (1994). Progesterone facilitates cognitive recovery and reduces secondary neuronal loss caused by cortical contusion injury in male rats. Exp. Neurol. 129, 64-69.

Roof, R.L., Hoffman, S.W. and Stein, D.G., (1997). Progesterone protects against lipid peroxidation following traumatic brain injury in rats. Mol. Chem. Neuropathol. 31:111 .

Roof, R.L., Duvdevani, R. and Stein, D.G., (1993). Gender influences outcome of brain injury: progesterone plays a protective role. Brain Res. 607:333-336.

Schumacher, M., Guennoun, R., Robert, F., Carelli, C., Gago, N., Ghoumari, A., Gonzalez Deniselle, M.C., Gonzalez, S.L., Ibanez, C., Labombarda, F., Coirini, H., Baulieu, E.E. and De Nicola, A.F., (2004). Local synthesis and dual actions of progesterone in the nervous system: neuroprotection and myelination. Growth Horm. IGF Res. 14:18-33.

Shear, D.A., Galani, R., Hoffman, S.W. and Stein, D.G., (2002). Progesterone protects against necrotic damage and behavioral abnormalities caused by traumatic brain injury. Exp. Neurol. 178:59-67.

Singh, M., (2006). Progesterone-induced neuroprotection. Endocrine 29:271-274.

Sperandio, S., Poksay, K.S., Schilling, B., Crippen, D., Gibson, B.W. and Breseden, D.E., (2010). Identification of new modulators and protein alterations in non-apoptotic programmed cell death. J.Cell. Biochem. 111:1401-1412.

Stein, D.G., (2008). Progesterone exerts neuroprotective effects after brain injury. Brain Res. Rev. 57:386-397.

Stein, D.G., (2011). Progesterone in the treatment of acute traumatic brain injury: a clinical perspective and update. Neuroscience 191:101-106.

Stein, D.G. and Wright, D.W., (2010). Progesterone in the clinical treatment of acute traumatic brain injury. Expert Opin. Investig. Drugs 19:847-857.

Stevens, S.J. and Harden, C.L., (2011). Hormonal therapy for epilepsy. Curr. Neurol. Neurosci. Rep. 11:435-442.

Thomas, A.J., Nockels, R.P., Pan, H.Q., Shaffrey, C.I. and Chopp, M., (1999). Progesterone is neuroprotective after acute experimental spinal cord trauma in rats. Spine 24:21342138.

Ungard, J.T., Beekman, M., Gasior, M., Carter, R.B., Dijkstra, D. and Witkin, J.M., (2000). Modification of behavioral effects of drugs in mice by neuroactive steroids. Psychopharmacology (Berl.) 148:336-343.

Vandenabeele, P., Galluzzi, L.,Vanden Berghe,T. and Kroemer, G., (2010). Molecular mechanisms of necroptosis: an ordered cellular explosion. Nat. Rev. Mol. Cell Biol. 11:700-714.

Veiga, S.,Garcia-Segura, L.M. and Azcoitia, I., (2003). Neuroprotection by the steroids pregnenolone and dehydroepiandrosterone is mediated by the enzyme aromatase. $J$. Neurobiol. 56:398-406.

Verrotti, A., Laus, M., Coppola, G., Parisi, P., Mohn, A. and Chiarelli, F., (2010). Catamenial epilepsy: hormonal aspects. Gynecol. Endocrinol. 26:783-790.

Weir, C.J., Ling, A.T., Belelli, D., Wildsmith, J.A., Peters, J.A. and Lambert, J.J., (2004). The interaction of anaesthetic steroids with recombinant glycine and GABAA receptors. Br. J. Anaesth. 92:704-711.

Weill-Engerer, S., David, J.P., Sazdovitch,V., Liere, P., Eychenne, B., Pianos, A., Schumacher, M., Delacourte, A., Baulieu, E.E. and Akwa, Y., (2002). Neurosteroid quantification in human brain regions: comparison between Alzheimer's and nondemented patients. $J$. Clin. Endocrinol. Metab. 87:5138-5143.

Wojtal, K., Trojnar, M.K. and Czuczwar, S. J., (2006). Endogenous neuroprotective factors: neurosteroids. Pharmacol. Rep. 58:335-340.

Wright, D.W., Kellermann, A. L., Hertzberg, V.S., Clark, P. L., Frankel, M., Goldstein, F.C., 
Salomone, J.P., Dent, L.L., Harris, O.A., Ander, D.S., Lowery, D.W., Patel, M.M., Denson, D.D., Gordon, A.B., Wald, M.M., Gupta, S., Hoffman, S.W., Stein, D.G., (2006). Pro- TECT: a randomized clinical trial of progesterone for acute traumatic brain injury. Ann. Emerg. Med. 49:391-402.

Xiao, G., Wei, J., Yan, W., Wang, W. and Lu, Z., (2008). Improved outcomes from the administration of progesterone for patients with acute severe traumatic brain injury: a randomized controlled trial. Crit.Care 12:R61.

Xilouri, M. and Papazafiri, P., (2006). Anti-apoptotic effects of allopregnanolone on P19 neurons. Eur. J. Neurosci. 23:43-54.

Yakovlev, A.G. and Faden, A.I., (2004). Mechanisms of neural cell death: implications for development of neuroprotective treatment strategies. Neuro Rx 1:5-16.

Yao, X.L., Liu, J., Lee, E., Ling, G.S. and McCabe, J.T., (2005). Progesterone differentially regulates pro- and anti-apoptotic gene expression in cerebral cortex following traumatic brain injury in rats. J.Neurotrauma 22:656-668. 